\title{
Characteristics of particleboard made from recycled wood-waste chips impregnated with phenol formaldehyde resin
}

\author{
Te-Hsin Yang ${ }^{\mathrm{a}}$, Cheng-Jung Lin ${ }^{\mathrm{b}}$, Song-Yung Wang ${ }^{\mathrm{a}}$, Ming-Jer Tsai ${ }^{\mathrm{a}, *}$ \\ ${ }^{a}$ School of Forestry and Resource Conservation, National Taiwan University, Taipei, Taiwan, ROC \\ ${ }^{\mathrm{b}}$ Division of Forest Utilization, Taiwan Forestry Research Institute, Taipei, Taiwan, ROC
}

Received 1 July 2005; received in revised form 23 August 2005; accepted 26 August 2005

\begin{abstract}
The main purpose of this study was to manufacture water-resistant particleboard for use in kitchens and bathrooms, and as flooringbased material and in outdoor environments. The chips were from recycled wood wastes of different wood species. The chips were divided into coarse chips with dimensions of 5-8 mesh and fine chips of 8-20 mesh, then, these chips were immersed in water-soluble phenol formaldehyde (PF) resin solution at concentrations of $4.5 \%, 6.5 \%$ and $10 \%$. After 5 min, they were removed from the PF solution and dried in an oven until in a half-hardened condition. Three-layer mats with target densities of 0.70 and $0.80 \mathrm{~g} / \mathrm{cm}^{3}$ were formed by using fine chips for the face layer $(25 \%)$ and back layer $(25 \%)$ and coarse chips for the core layer $(50 \%)$. A conventional hot press was used for fabrication of the particleboard, and the temperature, pressure and pressing time were $453 \mathrm{~K}, 2.9 \mathrm{MPa}$, and $5 \mathrm{~min}$, respectively. The nominal dimensions of particleboard were $500 \times 500 \times 12 \mathrm{~mm}$ (thick).

Result showed that the PF resin absorption content of chips (RC) increased linearly with an increase in the concentration of PF solution. Their relationship could be represented by the linear regression formula. The bending strength, internal bonding strength, and thickness swelling ( $\%)$ of the PF-impregnated particleboards exhibited excellent performances compared to those made in the past, and the retention rate $(\%)$ of the modulus of rupture (MOR) and modulus of elasticity (MOE) of PF-impregnated particleboard after treatment in hot water $(343 \mathrm{~K})$ for $2 \mathrm{~h}$ were maintained at $48.7-84.5 \%$ and $49.2-82.7 \%$, respectively. Characteristics of the ultrasonic velocity in the mechanical direction were similar to those in the vertical direction. In addition, there were significant relationships between the ultrasonic velocity and the mechanical properties of the particleboard, and this meant that we could evaluate the properties of the particleboard using ultrasonic velocity.
\end{abstract}

(C) 2005 Elsevier Ltd. All rights reserved.

Keywords: Ultrasonic wave velocity; Bending strength; Internal bonding strength; Thickness swelling; Retention rate of bending strength

\section{Introduction}

Wooden materials in the building industry have always been popular in many countries as a result of their excellent properties. Due to its use for furniture, architecture, and indoor decoration, wood has always been the largest proportion of material used. According to information provided by the Industrial Pollution Control Crops (IPCC) [1], the wood consumption rate in 1989 was $3.5 \times 10^{9} \mathrm{~m}^{3}$.

\footnotetext{
*Corresponding author. Tel.: + 886233664641 ; fax: + 886223686335

E-mail addresses: d90625006@ntu.edu.tw (T.-H. Yang), tmj@ntu.edu.tw (M.-J. Tsai).
}

By 2010 , it is forecast to reach $5.1 \times 10^{9} \mathrm{~m}^{3}$. We can see from this that with the advance of human civilization, the consumption of wood has increased; in general, the use of this material creates a lot of wastes. In recent years, wood wastes have caused environmental concerns to move to the forefront in Taiwan.

Today, the topics of recycling systems and reuse techniques of wood wastes in Taiwan are widely discussed in public and are becoming increasingly important because $2-3 \times 10^{6} \mathrm{~m}^{3}$ of wood wastes are generated in Taiwan annually, and only $4.38-5.13 \%$ of these are recycled and reused. Furthermore, wood-based wastes such as flooring, ceiling, and decorations from construction and demolition 
sites comprise $10 \%$ of the total generated wastes by volume, only exceeded by concrete wastes. These woodbased wastes from construction and demolition sites are usually not included in any recycling lists. They are sent to either combustion facilities or landfills.

Recently, wooden wastes are being recycled into other wood products at an increasing rate. The topics of how to recycle wood residues into usable products have been studied for decades [2-4]. In these reuse products, particleboard has found typical applications as flooring, wall and ceiling panels, office dividers, bulletin boards, furniture, cabinets, counter tops, and desk tops [5], and it seems that the manufacture of particleboard from recycled woodbased wastes is the most common way to reuse them.

Moreover, a series of studies has been conducted to investigate the use of non-destructive evaluation (NDE) technologies to aid in wood-based product quality assessment [6-8]. These studies yielded similar results and established relationships between mechanical strength and dynamic properties.

The purpose of this study was to investigate the density, bending properties, internal bonding strength, and thickness swelling (TS) of particleboard made from different recycled wood species chips, which were impregnated with phenol formaldehyde (PF) resin. Furthermore, the properties after accelerated aging and the ultrasonic properties of the manufactured particleboard were also evaluated.

\section{Experimental materials and methods}

\subsection{Materials}

Chips from mixed hardwood species including oak (Quercus spp.) and lauan (Shorea spp.) were prepared from recycled new construction and demolition wastes which were gathered and then classified by Jen-Chun Enterprise in Feng-Yuan, Taiwan.

The adhesive used was a water-soluble PF resin (76-78\% solid content and $\mathrm{pH}$ 8-9 produced by Tai-Lin Resin, Co., Taipei, Taiwan).

\subsection{Production process of chips}

Chips were divided into four grades using 5, 8, and 20 meshes, and were divided into coarse chips which passed through 5 mesh stop on 8 mesh and fine chips with through 8 mesh stop on 20 mesh. The chips were oven-dried to 2-4\% moisture content (MC), at a temperature of $338 \pm 2 \mathrm{~K}$. Then, they were immersed in a water-soluble $\mathrm{PF}$ resin.

The PF resin absorption content can be expressed as

$\mathrm{RC}(\%)=\left(\frac{W_{2}-W_{1}}{W_{1}}\right) \times 100$,

where $\mathrm{RC}$ is the PF absorption content, $W_{1}$ is the ovendried weight of the chips before impregnation, and $W_{2}$ is the oven-dried weight of chips after impregnation.
Next, the chips were dried in an oven until in a halfhardened condition, and then were placed into a frame of $50 \times 50 \mathrm{~cm}$. The particleboard was formed using fine chips for the face layer $(25 \%)$ and back layer $(25 \%)$ and coarse chips for the core layer $(50 \%)$. A conventional hot press was used for fabrication of the particleboard and the temperature, pressure and pressing time were $453 \mathrm{~K}$, $2.9 \mathrm{MPa}$ and $5 \mathrm{~min}$, respectively. The nominal dimensions of particleboard were $500 \times 500 \times 12 \mathrm{~mm}$ (thick), with three layers. The thickness of particleboard was controlled by stop bars. Two kinds of target densities of particleboard (D1 group was $0.8 \mathrm{~g} / \mathrm{cm}^{3}$, and D2 group was $0.7 \mathrm{~g} / \mathrm{cm}^{3}$ ) were fabricated in this study.

\subsection{Testing method}

The particleboards produced for this study, were tested under the American Society Testing and Materials (ASTM) method standard D-1037 [9], in conducting various tests.

\subsubsection{Ultrasonic wave test}

Prior to testing, PF-impregnated particleboards were conditioned at $293 \mathrm{~K}$ and $65 \%$ relative humidity, and the full panels of each particleboard were prepared for the ultrasonic wave tests. The test points of two corresponding sides of a particleboard were considered the investigated points and at intervals of $50 \mathrm{~mm}$, an ultrasonic wave instrument (Pundit, $54 \mathrm{kHz}$, C.N.S. Electronic Ltd.) which sends an ultrasonic pulse through the specimen was used to measure the time required for the transmission of the pulse through the specimen. The ultrasonic velocity was then calculated from the length of the specimen divided by the propagation time.

After the ultrasonic investigation, the full piece of tested particleboard was cut into static bending specimens and internal bond (IB) strength specimens following ASTM D1037 [9], and their positions relative to the full piece of particleboard were recorded. These static bending specimens were first used to conduct an ultrasonic wave test to obtain the ultrasonic velocity (Vl) through the face direction using a Pundit ultrasonic apparatus at a frequency of $54 \mathrm{kHz}$. However, transit times of the ultrasonic pulse for IB specimens were measured at a frequency of $500 \mathrm{kHz}$ in the thick direction to the surface of each specimen by the Pundit ultrasonic apparatus. The velocity was then calculated by dividing the length. The waves traveled by the transit time. The ultrasonic velocity and dynamic modulus of elasticity (DMOE) were calculated by the following formulae:

$\mathrm{V} 1(\mathrm{Vt})(\mathrm{m} / \mathrm{s})=\frac{L}{t}$,

$\operatorname{DMOE}(\mathrm{MPa})=\mathrm{Vl}^{2} \times \rho$,

where $\mathrm{Vl}$ is the ultrasonic velocity in the face direction of particleboard, Vt is the ultrasonic velocity in thick 
direction of particleboard, $L$ is the length, $t$ is the transit time, DMOE is the dynamic modulus of elasticity, $\rho$ is the density.

\subsubsection{Density and moisture content}

Fabricated particleboards, placed under room humidity for 1 week, were tested for their density and MC, which used the following formulae:

Air-dried density $\left(\mathrm{g} / \mathrm{cm}^{3}\right)=\frac{W_{\mathrm{a}}}{V_{\mathrm{a}}}$,

Moisture content $(\%)=\frac{W_{\mathrm{a}}-W_{0}}{W_{0}} \times 100$,

where $W_{\mathrm{a}}$ is the air-dried weight, $V_{\mathrm{a}}$ is the air-dried volume, and $W_{0}$ is the oven-dried weight of the particleboard.

\subsubsection{Static bending test}

After the ultrasonic wave test for obtaining the ultrasonic velocity, the conditioned samples, $7.62 \times 20.32 \mathrm{~cm}$ $(3 \times 8$ in), two from each of two panels, were tested for the modulus of rupture (MOR) and modulus of elasticity (MOE) per ASTM standard D-1037-96 [9]. The MC, nominal thickness, and density were determined for these specimens.

The MOR and MOE of each specimen are represented by the following formulae:

$\operatorname{MOR}(\mathrm{MPa})=\frac{3 P_{\mathrm{b}} L}{2 b h^{2}}$,

$\operatorname{MOE}(\mathrm{MPa})=\frac{P_{\mathrm{bp}} L^{3}}{4 b h^{3} Y_{\mathrm{p}}}$,

where MOR is static bending strength (MPa), MOE is static bending modulus of elasticity $(\mathrm{MPa}), P_{\mathrm{b}}$ is maximum load $(\mathrm{N}), P_{\mathrm{bp}}$ is the load at the proportional limit $(\mathrm{N}), Y_{\mathrm{p}}$ is the deflection corresponding to $P_{\mathrm{bp}}(\mathrm{mm}), b$ is the width of the specimen $(\mathrm{mm}), h$ is the thickness of the specimen $(\mathrm{mm})$, and $L$ is the span (mm).

\subsubsection{Internal bond strength}

The tensile strength perpendicular to the surface was determined using nine square conditioned specimens of $5.08 \times 5.08 \mathrm{~cm}(2 \times 2$ in $)$ from each panel according to ASTM standard D-1037-96 [9]. The rupture load $\left(P_{\mathrm{s}}\right)$ was determined and IB strength was calculated from the following formula:

$\mathrm{IB}(\mathrm{MPa})=\frac{P_{\mathrm{s}}}{b l}$,

where IB is the internal bond strength, $P_{\mathrm{s}}$ is the rupture load, and $l$ is the length of the specimen. However, the ultrasonic velocity of IB specimens was detected as described above before the IB test.

\subsubsection{Thickness swelling}

Conditioned samples, $15.24 \times 15.24 \mathrm{~cm}(6 \times 6$ in $)$ for the evaluation of TS were prepared according to ASTM standard D-1037-96 [9]. The thickness at the middle of the test specimen was measured with a micrometer. Then, the test specimens were placed parallel into the water for $30 \mathrm{~mm}$ and soaked for 2 and $24 \mathrm{~h}$ for measurement of the thickness. The TS rate was determined from the following formula:

$\mathrm{TS}_{2}(\%)=\frac{t_{2}-t_{0}}{t_{0}} \times 100$,

$\mathrm{TS}_{24}(\%)=\frac{t_{24}-t_{0}}{t_{0}} \times 100$,

where TS is the thickness swelling rate, $t_{0}$ is thickness at the middle of the test specimen before soaking in the water, and $t_{2}$ and $t_{24}$ are the thicknesses in the middle of the test specimen after soaking into water for 2 and $24 \mathrm{~h}$, respectively.

\subsubsection{Accelerated degradation tests}

Specimens were soaked in hot water $(343 \mathrm{~K})$ for $2 \mathrm{~h}$ and then soaked in cold water (at room temperature) for $1 \mathrm{~h}$ for cooling. The static bending tests were conducted on specimens while they were in a wet condition. The MOR and MOE retention rates were evaluated from the following formula:

MOR retention rate $(\%)=\frac{\mathrm{MOR}_{2}}{\mathrm{MOR}_{1}} \times 100$,

MOR retention rate $(\%)=\frac{\mathrm{MOE}_{2}}{\mathrm{MOE}_{1}} \times 100$,

where $\mathrm{MOR}_{1}, \mathrm{MOE}_{1}, \mathrm{MOR}_{2}$ and $\mathrm{MOE}_{2}$ represent the MOR and MOE values in an air-dried condition and after soaking in hot water $(343 \mathrm{~K})$ for $2 \mathrm{~h}$, respectively.

\section{Results and discussion}

\subsection{PF resin absorption content}

In this study, chips of mixed wood species were immersed in a water-soluble PF resin solution with concentrations of $10 \%$ (P10 group), 6.5\% (P6 group), and $4.5 \%$ (P4 group) for $5 \mathrm{~min}$. It was found that the PF resin absorption content increased linearly with an increase in the treatment concentration (Fig. 1). The previous study also indicated that a high correlation $\left(r^{2}=0.934-0.969\right)$ existed between the PF resin absorption content and treatment concentration for the oriented strand board (OSB) [10].

\subsection{Ultrasonic velocity obtained from the full piece particleboard}

Values of the ultrasonic velocity $(V)$ obtained from the full-piece specimen at intervals of $5 \mathrm{~cm}$ in the mechanical direction or vertical direction are shown in Fig. 2. It was obvious that the ultrasonic velocity which propagated through the mechanical direction was similar to that in the 
vertical direction. This means that the $V$ value was not affected by the resin content of the chips. The particleboard manufactured in our study had no orthotropic properties,

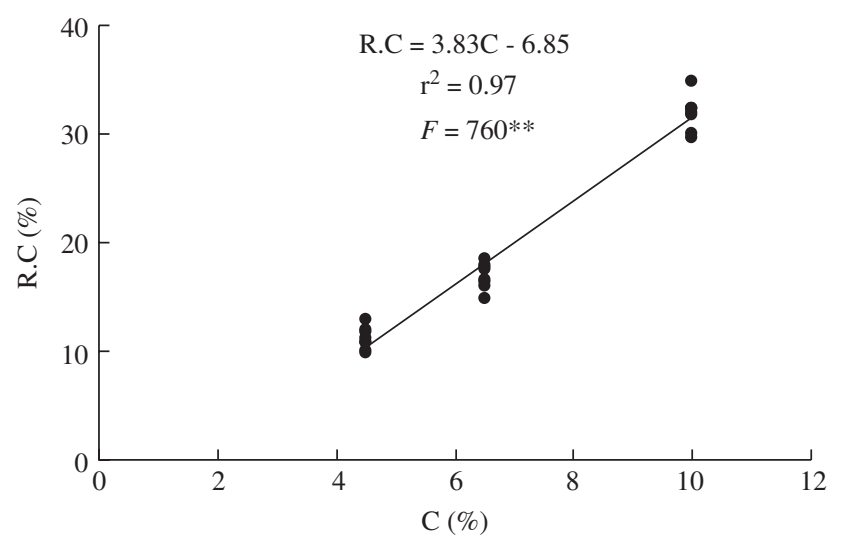

Fig. 1. Relationship between resin content (RC) and treatment concentration $(C)$.

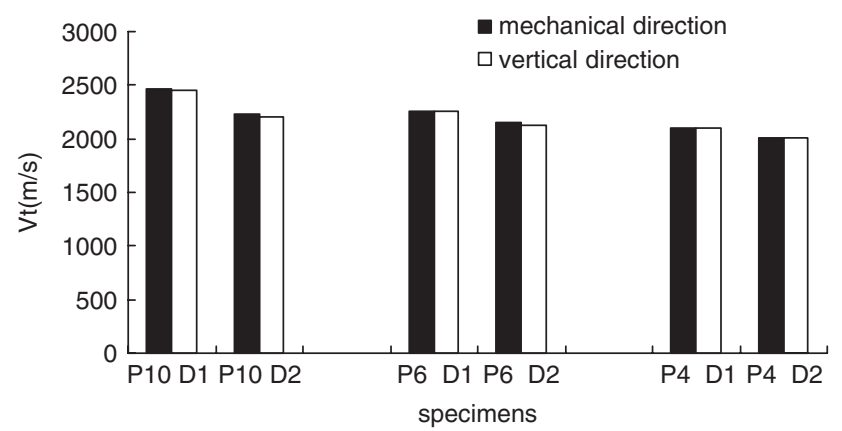

Fig. 2. Ultrasonic velocity for PF resin-impregnated particleboard in mechanical and vertical directions. P10D1: D1 group whose particles are impregnated with $10 \% \mathrm{PF}$ resin; P6D1: D1 group whose particles are impregnated with $6.5 \%$ PF resin; P4D1: D1 group whose particles are impregnated with $4.5 \% \mathrm{PF}$ resin; $\mathrm{P} 10 \mathrm{D} 2$ : $\mathrm{D} 2$ group whose particles are impregnated with $10 \% \mathrm{PF}$ resin; P6D2: D2 group whose particles are impregnated with $6.5 \%$ PF resin; P4D2: D2 group whose particles are impregnated with $4.5 \% \mathrm{PF}$ resin. which exist on the surfaces of OSB and plywood [10-12]. In a comparison to our former studies $[10,18,19]$, the ratio of ultrasonic velocity of $\mathrm{PF}$ resin-impregnated OSB and particleboard was about 2:1.

In a study by Yang et al. [10], the value of the ultrasonic velocity of PF resin-impregnated OSB in the flake length direction was not affected by the resin content of the flakes. This may have been the reason that the value of ultrasonic velocity of the flakes was greater than that of the PF resin. However, values of the ultrasonic velocity of PF resinimpregnated particleboard of the D1 (density was $0.8 \mathrm{~g} / \mathrm{cm}^{3}$ ) and D2 groups (density was $0.7 \mathrm{~g} / \mathrm{cm}^{3}$ ) increased linearly with increase in the concentration of the PF solution (Table 1). The value of the ultrasonic velocity of specimens of the D1 group, which were denser, was more significantly affected by the concentration of the PF solution. This is because the dimension of the chips was small, irregular, and anisotropic. The effect of fiber direction on the ultrasonic velocity was not obvious at any $\mathrm{PF}$ resin contents.

However, the ultrasonic wave velocity which propagated through the thick direction of the particleboard (Vt) increased linearly with an increase in the PF resin absorption content of the chips (Table 1). A good correlation $\left(r^{2}=0.54\right)$ was also found between PF resin absorption content and $\mathrm{Vt}$ for the OSB in a study [10].

\subsection{Bending strength properties of particleboard}

Values of MOR and MOE of the PF-impregnated particleboard are shown in Table 2. It was found that in the D1 group, density $(\rho)$ was $0.80 \mathrm{~g} / \mathrm{cm}^{3}$, the MOR range from 14.6 to $29.0 \mathrm{MPa}$, and the MOE range from 3136.0 to $5331.2 \mathrm{MPa}$; whereas in the D2 group, $\rho$ was $0.70 \mathrm{~g} / \mathrm{cm}^{3}$, the MOR range from 11.1 to $18.0 \mathrm{MPa}$, and the MOE range from 1734.6 to $3224.2 \mathrm{MPa}$. The results indicated that the values of MOR and MOE of PF resin-impregnated particleboards manufactured in our study were higher than

Table 1

Correlation among resin content (RC), ultrasonic wave velocity ( $V$ ), modulus of rupture (MOR), modulus of elasticity (MOE), dynamic modulus of elasticity (DMOE) and internal bonding strength (IB) analyzed by linear regression $(Y=A X+B)$ formulae for PF resin-impregnated particleboard

\begin{tabular}{|c|c|c|c|c|c|c|}
\hline Sample & $Y$ & $X$ & $A$ & $B$ & $r^{2}$ & $F$ values \\
\hline \multirow[t]{5}{*}{ D1 group } & $\mathrm{Vl}$ & $\mathrm{RC}$ & 17.76 & 1914 & 0.80 & $211^{* *}$ \\
\hline & $\mathrm{Vt}$ & $\mathrm{RC}$ & 11.11 & 808 & 0.78 & $55^{* *}$ \\
\hline & MOR & $\mathrm{Vl}$ & 0.03 & -61.3 & 0.93 & $475^{* *}$ \\
\hline & MOE & $\mathrm{Vl}$ & 5.3 & -9291.5 & 0.85 & $189^{* *}$ \\
\hline & IB & $\mathrm{Vt}$ & 0.005 & -3.48 & 0.87 & $225^{* *}$ \\
\hline \multirow[t]{5}{*}{ D2 group } & $\mathrm{Vl}$ & $\mathrm{RC}$ & 9.94 & 1919 & 0.65 & $95^{* *}$ \\
\hline & $\mathrm{Vt}$ & $\mathrm{RC}$ & 11.89 & 717 & 0.82 & $73^{* *}$ \\
\hline & MOR & $\mathrm{Vl}$ & 0.02 & -26.6 & 0.71 & $68^{* *}$ \\
\hline & MOE & $\mathrm{Vl}$ & 4.42 & -7306.8 & 0.89 & $222^{* *}$ \\
\hline & IB & $\mathrm{Vt}$ & 0.004 & -2.71 & 0.73 & $91^{* *}$ \\
\hline
\end{tabular}

Vl: ultrasonic velocity propagated through the face direction of the particleboard.

Vt: ultrasonic velocity propagated through the thick direction of the particleboard.

**: Significant difference at the $1 \%$ level $(P<0.01)$. 


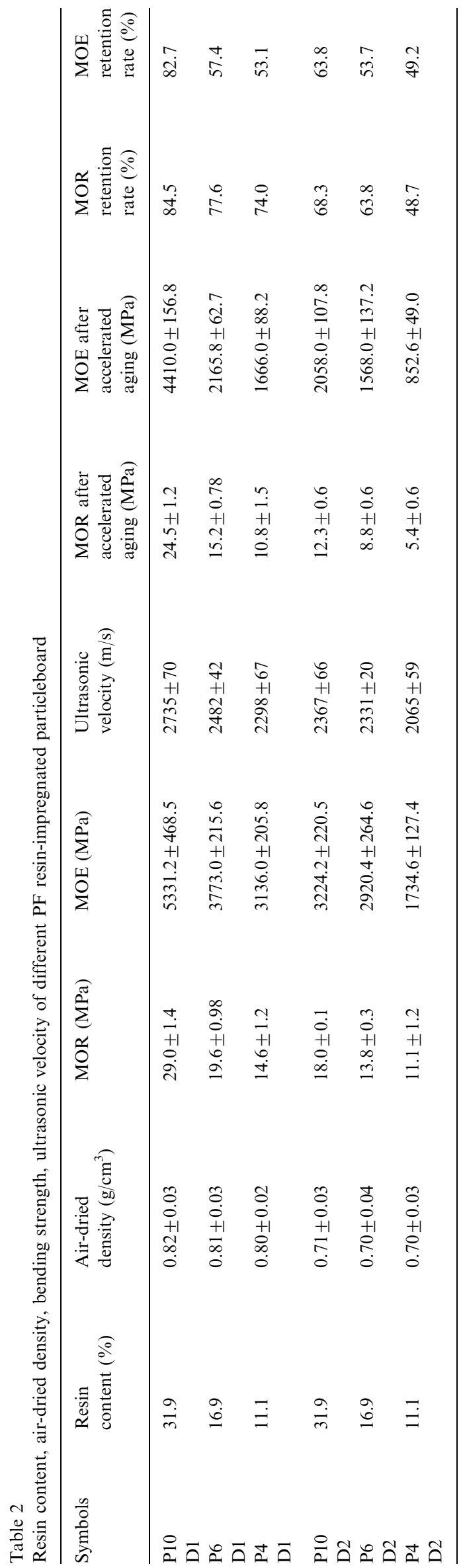

those of urea adhesives sprayed particleboards [13], whose MOR range from 9.9 to $11.2 \mathrm{MPa}$; similar results were also obtained for particleboard made out of Korea pruning logs [14]. This means that the PF resin-impregnated chips using the manufacturing process of particleboard under a hot press $(453 \mathrm{~K})$ showed plasticity and flow ability. After the hot press process, the distribution of $\mathrm{PF}$ resin on the surface and back of the particleboard could be more even and dense, and values of the MOR and MOE thus could be even higher [10]. Some studies on the density profile also indicated that the bending strength depends on the pick density, mean density (MD), and other density parameters. Wong et al. [15] indicated that peak density (PD) has relative higher effect on both MOR and MOE at high MD level, whose $r$ values were 0.875 and 0.954 , respectively. Wong et al. [16] indicated that PD, MD, and peak distance (Pdi) were the density factors affecting $\operatorname{MOE}\left(r^{2}=0.998\right)$, and increment in PD leads to a proportional increase in MOE.

It was found that the values of MOR and MOE increased linearly with an increase of the values of the ultrasonic velocity (Vl), as can be seen from Table 1. This means that the values of ultrasonic velocity (Vl) can be considered as an evaluation index of the static bending strength of the particleboard. When comparing DMOE and MOE, it is evident that the DMOE was higher than the MOE. It was also found that the relation between the DMOE and MOE was significant (Fig. 3).

\subsection{Internal bond strength}

A higher value of the IB strength of different PFimpregnated particleboard groups was observed in our study because of the even distribution of the PF resin on the chips. The IB of groups D1 and D2 reached 0.67-1.86 and $0.59-1.72 \mathrm{MPa}$, respectively. The IB values of PFimpregnated particleboard in our study were superior to those $(0.12-0.42 \mathrm{MPa})$ of particleboards manufactured by $\mathrm{PF}$ resin sprayed [13] compared to the particleboard made by mixed species [17] which included pines, aspens, oaks and other hardwoods. The IB value in our study was also higher than theirs $(\mathrm{IB}=0.56 \mathrm{MPa})$.

Moreover, values of IB increased linearly with an increase in the values of the ultrasonic wave velocity $(\mathrm{Vt})$ which propagated through the thick direction of the particleboard (Table 3). This result is in agreement with a previous report [7] in which a high correlation existed between the ultrasonic velocity measured in the length or thickness direction and the IB for the particleboard, the $r$ values were 0.81 and 0.96 , respectively. The previous studies also indicated that a high correlation existed between the values of the ultrasonic wave velocity $(\mathrm{Vt})$ propagated through the thick direction and IB of PF resinimpregnated OSB $[10,18,19]$. This suggests that the ultrasonic velocity could be utilized satisfactorily to assess the IB of the boards. 


\subsection{Thickness swelling}

Results showed that the values of TS of particleboards manufactured in our study for groups D1 and D2 were lower than $12 \%$ (Fig. 4). Fig. 4 also showed that the TS decreased linearly with an increase in the treatment concentration of the PF solution, namely the PF resin content. Halligan [20] indicated two opposing mechanisms for TS, densification and resin efficiency, and a higher compaction ration improved the efficiency of adhesive bonds, which would reduce the TS. In our study, we found the TS of group D2 $\left(\rho=0.7 \mathrm{~g} / \mathrm{cm}^{3}\right)$ was lower than that of the group D1 $\left(\rho=0.8 \mathrm{~g} / \mathrm{cm}^{3}\right)$. This was because when the same density wood materials are dominant in a process, the compaction ratio increases, which increases the TS. A highly negative correlation between the values of the ultrasonic wave velocity $(\mathrm{Vt})$ which propagated through the thick direction and TS for the PF resin-impregnated particleboard was also observed in our study (Fig. 5).

\subsection{Accelerated degradation tests}

Values of the bending strength (MOR and MOE) of PF resin-impregnated particleboard after treatment in hot water $(343 \mathrm{~K})$ for $2 \mathrm{~h}$ are shown in Table 2 . A similar correlation existed between the MOR and MOE retention rates $(\%)$ of OSB and the PF resin content, after $2 \mathrm{~h}$ at $343 \mathrm{~K}$. [10] However, the $\mathrm{MOR}_{\|}$and $\mathrm{MOE}_{\|}$(specimens

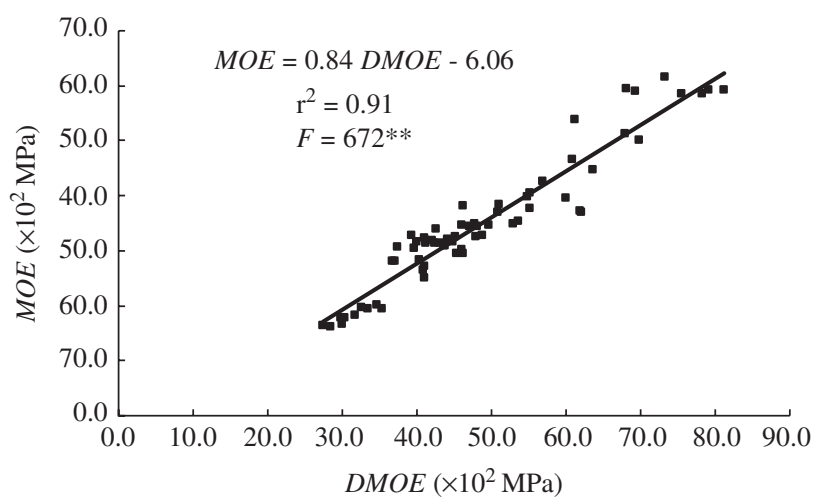

Fig. 3. Relationship between modulus of elasticity (MOE) and dynamic modulus of elasticity (DMOE). with grain direction of face parallel to length axis) retention rates $(\%)$ of the $\mathrm{PF}$ resin-impregnated OSB were maintained at $75.9-95.6 \%$ of the $\mathrm{MOR}_{\|}$for Japanese cedar OSB, at $60.2-88.3 \%$ of the $\mathrm{MOR}_{\|}$for Shorea OSB, at $54.5-84.6 \%$ of the $\mathrm{MOE}_{\|}$for Japanese cedar OSB, at $26.8-82.1 \%$ of the $\mathrm{MOE}_{\|}$for Lauan OSB. The bending strength retention rate $(\%)$ decreased with a decrease in the resin content. However, the $\mathrm{MOR}_{\|}$retention rate $(\%)$ of $\mathrm{PF}$ resin-impregnated OSB remained above $50 \%$ [10].

Sekino [21] indicated that the MOR retention rate $(\%)$ of MDF and particleboard in a wet condition decreased linearly with an increase in the TS. In service conditions, values of TS were $8 \%$ for MDF and $14 \%$ for particleboard, assuming the retention rate (\%) of MOR was $60 \%$.

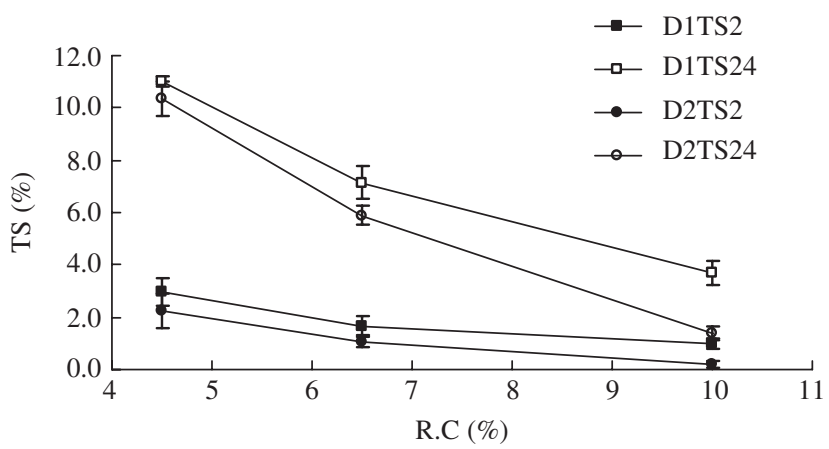

Fig. 4. Relationship between thickness swelling (TS) and resin content (RC).

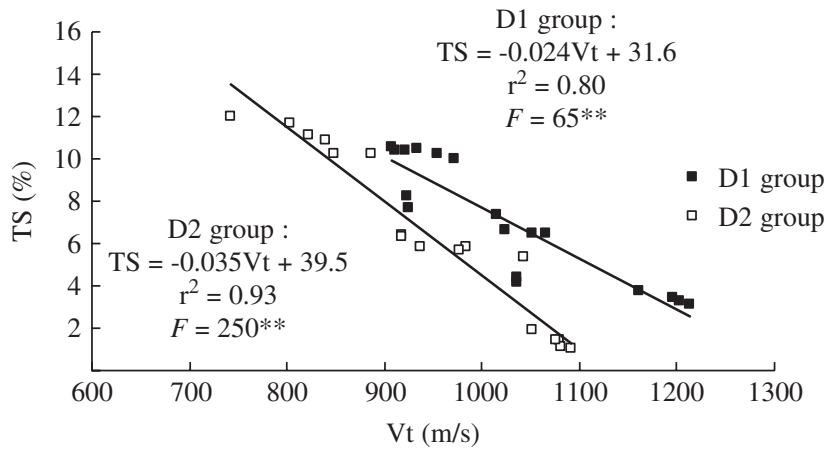

Fig. 5. Relationship between thickness swelling (TS) and ultrasonic velocity through the thick direction $(\mathrm{Vt})$.

Table 3

Correlation among modulus of rupture retention $\operatorname{MOR}(\%)$, modulus of elasticity retention MOE(\%), and thickness swelling (TS), analyzed by the linear regression $(Y=\mathrm{AX}+\mathrm{B})$ formulae for $\mathrm{PF}$ resin-impregnated particleboard

\begin{tabular}{lllllll}
\hline Sample & $Y$ & $X$ & $A$ & $B$ & $r^{2}$ & \\
\hline D1 group & MOR (\%) & TS & -1.65 & 90.37 & 0.63 & $32^{* *}$ \\
& MOE (\%) & TS & -4.48 & 96.42 & $70^{* *}$ \\
D2 group & MOR (\%) & TS & -2.04 & 72.45 & 79 & 0.82 \\
& MOE (\%) & TS & -1.61 & 65.49 & 0.66 \\
\hline
\end{tabular}

D1 group: The particleboard had a density of $0.8 \mathrm{~g} / \mathrm{cm}^{3}$.

D2 group: The particleboard had a density of $0.7 \mathrm{~g} / \mathrm{cm}^{3}$.

**: Significant difference at the $1 \%$ level $(P<0.01)$. 
The relationship between TS and the MOR (MOE) retention rate is shown in Table 3. It was found that MOR $(\%)$ and MOE (\%) decreased linearly with an increase in the TS. A negative regression analysis was performed to determine the correlation between MOR (\%) and MOE (\%) and TS (Table 3). As TS reached 10\%, MOR and MOE retention rates in group D1 were, respectively, 74\% and $52 \%$, as for group D2, the MOR and MOE rates were $52 \%$ and $50 \%$. However, its retention rate fell below $50 \%$.

\section{Conclusions}

This study focused on investigating the properties of PF resin-impregnated particleboard produced using recycled wood-waste particles, and results showed that the values of MOR, IB, and TS of PF-impregnated particleboards were superior to those of conventionally manufactured particleboard. In addition, the positive relationships between the resin content of the chips and the MOR, MOE, and IB values could be represented by linear regression formulae, however, the TS of PF resin-impregnated particleboards decreased linearly with an increase in the PF resin content of the chips (RC). The retention rates (\%) of MOR and MOE of PF resin-impregnated particleboard after treatment in hot water $(343 \mathrm{~K})$ for $2 \mathrm{~h}$ were maintained at a range from $48.7 \%$ to $84.5 \%$ and from $49.2 \%$ to $82.7 \%$, respectively.

The ultrasonic wave velocity (Vl) which propagated through the face direction increased linearly with increases in the bending strength, in the internal bonding strength, and the retention rate of the bending strength. However, the ultrasonic wave velocity $(\mathrm{Vt})$ which propagated through the thick direction of the particleboard increased linearly with a decrease in the thickness swelling. This suggests that ultrasonic velocity can satisfactorily be utilized to assess the properties of PF resin-impregnated particleboard.

\section{References}

[1] Industrial Pollution Control Corps. Recycle and reuse of wood-waste materials. Taipei, Taiwan: Industrial Development Bureau Ministry of Economic Affairs; 1996. p. 15-41.

[2] Bell RG, Pos J, Lyon RJ. Production of compost from softwood lumber mill waste. Compost Science 1973;14(2):5-7.
[3] Clausen CA. Removal from treated wood using a dual remediation process. Waste Management Research 2000;18:1-5.

[4] Khedari J, Nankongnab N, Hirunlabh J, Teekasap S. New low-cost insulation particleboards from mixture of durian peel and coconut coir. Building and Environment 2004;39:59-65.

[5] Wang D, Sun XS. Low density particleboard from wheat straw and corn pith. Industrial Crops and Products 2002;15:47-50.

[6] Ross RJ, Pellerin RF. NDE of wood based composites with longitudinal stress wave. Forest Products Journal 1988;38(5):39-45.

[7] Sun YC, Arima T. Structural mechanics of wood composite material: ultrasonic evaluation of internal bond strength daring an accelerated aging test. Journal of Wood Science 1998;44(3):348-53.

[8] Sun YC, Arima T. Structural mechanics of wood composite material: ultrasonic propagation mechanism and internal bonding of particleboard. Journal of Wood Science 1999;45(2):221-6.

[9] American Society Testing and Materials (ASTM). Methods D-1037. Evaluating the properties of wood based fiber and particleboard material. 1996.

[10] Yang TH, Tsai MJ, Wang SY. Characteristics of OSB made from PFresin impregnated flakes. Forest Products Industries 2001;20(3): 227-37.

[11] Jung JY, Chen TY. Detecting the anisotropic characteristics of woodbased panels by stress wave NDT methods. Forest Products Industries 1996;15(4):574-85.

[12] Chen TY, Ting LC, Chen HC. Comparison of destructive and nondestructive test on commercial overlaid wood based panels. Forest Products Industries 2000;19(4):441-9.

[13] Wang SY, Chen BJ. Studies on the application of Japanese-Fir particle for the improvement of domestic particleboard processing properties. Forest Products Industries 1986;5(1):2-14.

[14] Oh YS, Cha JK, Kwak JH. Properties of particleboard from Korea pruning logs. Forest Product Journal 2003;53(1):67-9.

[15] Wong ED, Zhang M, Wang Q, Kawai S. Formation of the density profile and its effects on the properties of particleboard. Wood Science and Technology 1999;33:327-40.

[16] Wong ED, Yang P, Zhang M, Wang Q, Nakao T, Li KF, et al. Analysis of the effects of density profile on the bending properties of particleboard using finite element method (FEM). Holz als Roh-und Werkstoff 2003;61:66-72.

[17] $\mathrm{Xu} \mathrm{W}$, Suchsland O. Variability of particleboard properties from single- and mixed-species processes. Forest Products Journal 1998; 48(9):68-74.

[18] Yang TH, Chen BJ, Wang SY. Properties of the light weight OSB made from PF-resin impregnated flakes. Forest Products Industries 2002;21(1):39-50.

[19] Yang TH, Chen HC, Wang SY, Tsai MJ. Characteristics of veneer overlaid OSB by using nondestructive test method. Quarterly Journal of Chinese Forestry 2003;36(2):199-209.

[20] Halligan AF. A review of thickness swelling in particleboard. Wood Science and Technology 1970;4(4):301-12.

[21] Sekino N. Performance of construction particleboard. Prediction of bending in service by water-immersion accelerated-aging treatment. Mokuzai Gakkishi 1986;32(4):280-4. 